\title{
Radio over Fiber Architecture Very High-Speed Wireless Communications in the Unlicensed 60 GHz Band
}

\author{
Raoule J. O. Agoua1* ${ }^{*}$, Aladji Kamagaté1, Adama Konaté1, Mourad Menif'², Olivier Asseu ${ }^{1}$ \\ ${ }^{1}$ Ecole Supérieure Africaine des Technologies de l'Information et de la Communication, LASTIC, Abidjan, Côte d'Ivoire \\ ${ }^{2}$ GRESCOM Laboratory, Higher School of Communications of Tunis, Ariana, Tunisia \\ Email: *raoule.agoua@esatic.edu.ci
}

How to cite this paper: Agoua, R.J.O., Kamagaté, A., Konaté, A., Menif, M. and Asseu, O. (2020) Radio over Fiber Architecture Very High-Speed Wireless Communications in the Unlicensed $60 \mathrm{GHz}$ Band. Optics and Photonics Journal, 10, 29-40. https://doi.org/10.4236/opj.2020.103003

Received: February 18, 2020

Accepted: March 23, 2020

Published: March 26, 2020

Copyright $\odot 2020$ by author(s) and Scientific Research Publishing Inc. This work is licensed under the Creative Commons Attribution International License (CC BY 4.0).

http://creativecommons.org/licenses/by/4.0/

\begin{abstract}
Larger wireless access networks are required to meet the growing demand for mobile traffic and multimedia services. The use of RoF (Radio over Fiber) technology in combination with millimeter waves is a potential response to the requirements of broadband applications and high capacity networks. In this paper, we proposed a RoF architecture able to provide very high-speed wireless access points up to Gbps considering an indoor and outdoor environment conform to IEEE 802.11ad and IEEE 802.15.3c standard. Optical transmission and radio coverage have been studied by considering the uplink and downlink. System performance has been evaluated in the relation to the Error Vector Magnitude (EVM) for various modulation formats (BPSK, QPSK and 16QAM). Results showed that millimeter wave signals are successfully delivered over a $50 \mathrm{~km}$ fiber link and a wireless channel up to $32 \mathrm{~m}$. Data throughput up to 5.28 Gbps has been reached. The proposed architecture can extend the range of applications for wireless communications in association with the unlicensed $60 \mathrm{GHz}$ band with the advantages of better capacity, a wider coverage area and a reduction in the investment cost.
\end{abstract}

\section{Keywords}

Radio over Fiber, Multi-Services, Millimeter Waves Band, Next Generation Networks

\section{Introduction}

The evolution of optical communication and the advent of 5th Generation networks have favored the emergence of new services and applications requiring communication rates up to Gbps, low latency and optimal quality of service. To meet these rapidly growing performance requirements, the millimeter wave 
spectrum must be increasingly used where larger bandwidths promise higher data rates and low latency communications [1].

The millimeter wave spectrum is widely available worldwide and offers 2.16 $\mathrm{GHz}$ bandwidth channels with very high transmission rates. However, there are some major disadvantages which are associated with the band around $60 \mathrm{GHz}$ related to the large losses in free space and the opacity of the walls at these frequencies [2]. A promising solution for the deployment of millimeter waves between multiple access points is offered by RoF technology [3]. RoF systems have been provided to essentially ensure the deployment of small cells and pico-cells for indoor and outdoor applications according to several RoF research works in the millimeter wave band [3] [4]. The use of small cells reduces interference, energy consumption and improves the quality of service by implementing femto-cells at the periphery of macro-cells. This also allows reduction of cell capacity and processing time. The target is to provide high data rates and large capacity applications using high modulation formats. It is also about improving the quality of service (QoS).

In [5], a RoF system using single carrier modulation (SCM) of QPSK, 16QAM and 64QAM was demonstrated and the study is mainly focused on wireless uplink transmission. System performance was evaluated by studying the magnitude of the error vector (EVM), the bit error rate (BER) and the signal to noise ratio (SNR). In [6], the authors experimentally demonstrated a RoF system using a 16-QAM signal at $5 \mathrm{Gbps}$ for a transmission distance of $100 \mathrm{~km}$ between the mobile service center and the base station using an optical carrier-suppressed transmitter at double sideband (DSB-SC) and an auto-heterodyne remote detection method (RSH). One of the major challenges of futuristic 5G transport networks is increasing network capacity. RoF systems could be combined with optical transport technology based on DWDM (dense wavelength division multiplexing) and PON (passive optical network) offering high capacity and excellent spectral efficiency over long distances [7] [8]. The authors proposed in [9], a multiservice RoF system comprising a central office (CO), a network based on PON technology, a remote access unit (RAU), a mobile transmitter/receiver $(\mathrm{MU})$. They integrate a remote node (RN) between the CO and the RAU in order to give certain flexibility to the RoF system and optimize the distribution of resources. In fact, the RN demultiplexes the wavelengths by using an Arrayed Wavelength Grid (AWG) to distribute channels to the corresponding RAU. In [10], a multiservice RoF system has been demonstrated. The authors used two separate wavelengths to manage the Wifi-WiMax service and the millimeter wave service separately. The data associated with the Wi-Fi, WiMax service are combined and modulated by an optical wavelength through a Mach-Zehnder Interferometer (MZI) using a single lateral band modulation (SSB). The millimeter wave service is modulated by another optical wavelength (Direct Modulation Laser, DML), routed to the RAU where it is transposed in the $60 \mathrm{GHz}$ band. System performance is assessed by measuring the magnitude of the error vector $(\mathrm{EVM})$ at the end-user level. The Wireless propagation distance is around $5 \mathrm{~m}$. 
The EVM sometimes also called relative constellation error (RCE) is used to quantify the performance of radio transmitter or receiver. Indeed, distortion, spurious signals, noise... degrade EVM, and therefore EVM provides a good understanding of the quality of the radio transmitter or receiver for use in digital communications.

The work presented in [11] studies high spectral efficiency RoF architecture with low energy consumption based on band mapping. Wifi-WiMax service and millimeter wave service are mapped together using sub-carrier multiplexing and double wavelength heterodyne beat techniques. The authors indicated that the proposed architecture meets the specifications of the passive optical network with wavelength division multiplexing (DWDM-PON). And then in [12], the authors demonstrated the support of handover for high mobility users using the Moving Extended Cell (MEC) concept through a new RoF architecture. In a recent work [13], the authors proposed a RoF system able to support multiservice (Wifi, WiMax, mm-Wave), multiband (2.4 GHz; $5.2 \mathrm{GHz}$; $60 \mathrm{GHz}$ ), multi modulation schemes (BPSK; QPSK; and 16 QAM) with multiple data up to 5 Gbps. The proposed architecture is based on a flat comb optical source (OFCS) generating 16 wavelengths spaced $12.5 \mathrm{GHz}$. The OSSB electro-optical modulation technique was used to generate several radio services combined with the same MZI modulator. System performance has been validated by measuring the EVM.

The research work of the RoF community aims at the implementation of a RoF system offering a high network capacity with flexibility based on a centralized architecture. The architectures proposed in the literature [11] [12] [13] show their capacity to support several services (Wifi, WiMax and mm-Waves) with different modulation formats. It has been shown that transmission rates of up to $5 \mathrm{Gbps}$ can be achieved using high modulation formats. However, the majority of the work and performances recorded have focused on the study of the downlink.

In this article, we propose a RoF architecture for $5 \mathrm{G}$ small cell transport networks. We are studying millimeter wave services in the unlicensed $60 \mathrm{GHz}$ band (57 - $66 \mathrm{GHz}$ ). We consider a bandwidth spectrum of $2.16 \mathrm{GHz}$, several modulation formats (BPSK, QPSK and 16 QAM) and a data rate of up to $5.28 \mathrm{Gbps}$. In order to take into account target standards, we focus here on short-range indoor link distribution by examining the uplink and downlink. System performance was assessed by measuring EVM for a fiber optic link length of $50 \mathrm{~km}$ between the optical transmitter and the RAU. The impact of the uplink on the downlink has also been studied. The document is structured as follows: Section 2 presents the configuration of the proposed RoF architecture. We present in Section 3 the results of the simulation and the performances obtained. Finally, the main conclusions are presented in Section 4.

\section{Bidirectional RoF Architecture in the $60 \mathrm{GHz}$ Band without License Proposed}

The proposed millimeter wave wireless fiber distribution system for uplink and 
downlink is illustrated in Figure 1. It is composed of a CO, PON, RN and several RAU. For the downflow, a single wavelength laser is used to generate a flat comb optical source in an OFCS system. It is a very practical technique to create a certain number of optical carriers. The system (OFCS) generates 16 optical carriers spaced $12.5 \mathrm{GHz}$ apart and then demultiplexed to be individually modulated by millimeter wave services. RF services in the $60 \mathrm{GHz}$ band according to the IEEE.802.11ad standard (F1 = 57.24 GHZ; F2 $=59.4 \mathrm{GHz}$; F3 $=61.56 \mathrm{GHz}$; $\mathrm{F} 4=63.72 \mathrm{GHz})$ are generated at intermediate frequencies $(\mathrm{IF} 1=8.32 \mathrm{GHz}$; IF2 $=10.48 \mathrm{GHz}$; IF3 $=2.64 \mathrm{GHz}$; IF4 $=4.8 \mathrm{GHz}$ ) then combined to modulate an optical carrier using OSSB modulation through a MZI. High modulation formats are used to increase network capacity and achieve speeds of up to 5.28 Gbps (BPSK, QPSK and 16 QAM). After that, the modulated optical carriers are combined using a multiplexer with a bandwidth of $12.5 \mathrm{GHz}$. They are then transmitted over a standard single-mode fiber (SSMF) to the RN where each modulated optical carrier is routed to a RAU.

At the RAU, the received multiband optical carrier is coupled to a local oscillator $(\mathrm{OL})$ to generate an optical heterodyne. An optical filter is used to select a wireless service and the laser (OL) which is launched in a photodiode (PD) to generate the modulated signal at $60 \mathrm{GHz}$. This signal is then amplified according to the specifications of standard [14] and then transmitted by an antenna to the user's mobile station (MU). The amplification varies according to the modulation format (variable gain of $8 \mathrm{~dB}$ ). This chosen configuration allows the RAU to be reconfigured and offers the possibility of reusing the frequencies. This is possible by adjusting the frequency of the transmitting carrier by a tunable laser. This gives the system greater flexibility for small cell system architectures. Also, the proposed model makes it possible to increase the throughput while using a reduced bandwidth of optoelectronic devices.

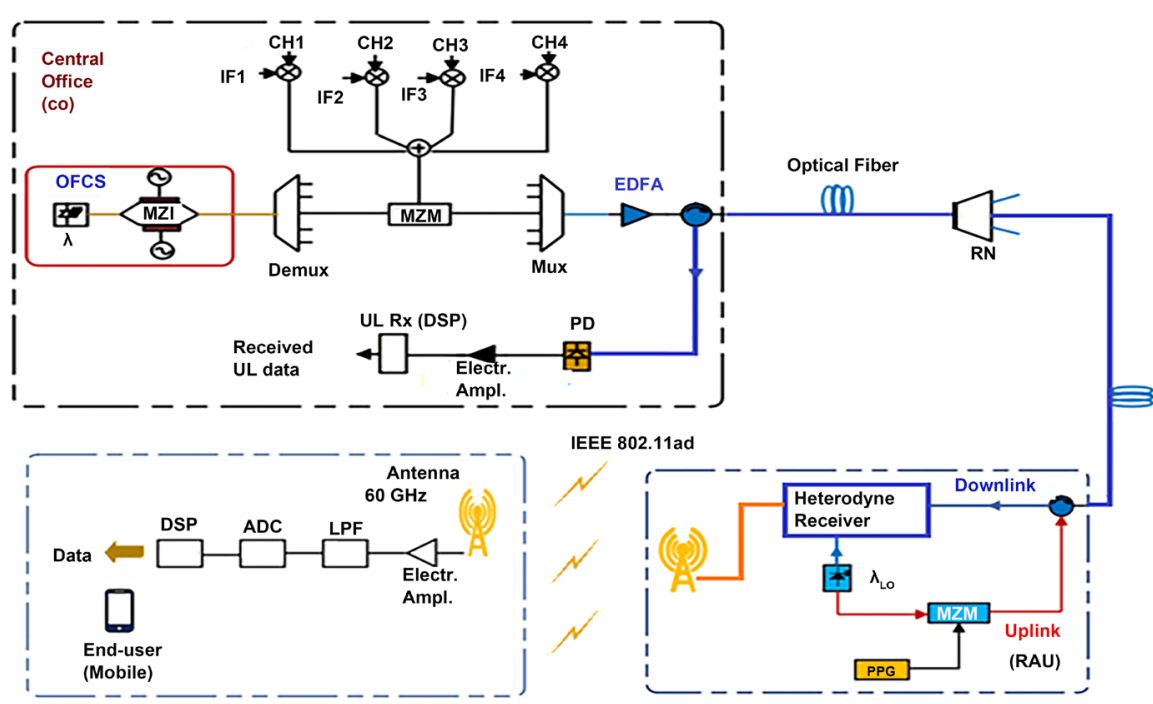

Figure 1. Architecture of the RoF system for the distribution of wireless access points in the $60 \mathrm{GHz}$ band. 
For the uplink flow, the received millimeter wave signal is detected by an envelope and electrically amplified before being used to drive an intensity modulator. The antenna is connected to a microwave circulator for the separation of the uplink and the downlink. The laser (OL) used for the uplink conversion of the downlink is also used for the uplink flow. Then, the baseband signal is transmitted over the same fiber to the central office where it is photo detected and demodulated.

\section{Experimental Configuration of the RoF System}

\subsection{Specification of the Standard in the Unlicensed $60 \mathrm{GHz}$ Band}

The specific standards for using the unlicensed millimeter waveband for WLAN and WPAN wireless local area networks are IEEE 802.11ad and IEEE 802.15.3c respectively. The IEEE 802.11 ad standard was published in 2008 by the ECMA 387 group concerning the use of the millimeter wave band in very high speed wireless local area networks (WLANs) [14] [15]. The regulations on the transmission powers authorized by the standard according to the regions are illustrated in [16]. The two standards operate on the same frequency band in the range of 57 to $66 \mathrm{GHz}$ and a comparative analysis shows that the two standards have almost the same bit rate and the same delay [17]. The sensitivity of millimeter wave receivers as a function of modulation formats is specified in [15].

According to the specifications, we consider in our implementation small cells [16] for outdoor applications of $100 \mathrm{~m}$ and indoor applications of $27 \mathrm{~m}$. In our work we are studying millimeter wave services in the unlicensed $60 \mathrm{GHz}$ band (57 - $64 \mathrm{GHz}$ ) offering $2.16 \mathrm{GHz}$ bandwidth channels. We therefore consider high modulation formats (BPSK, QPSK and 16 QAM) and bit rates up to 5.28 Gbps. The maximum transmission power is $36 \mathrm{dBm} /$ EIRP max. $52 \mathrm{dBm}$ with a reduction to $10 \mathrm{dBm}$. We consider that the receiver sensitivity is $-55 \mathrm{dBm}$ with an amplification whose gain range varies according to the modulation format (11dB).

\subsection{Configuration of the Parameters of the RoF System}

The experimental configuration of the proposed RoF system (Figure 1) takes into account the CO, RAU and the end user (MU). At CO level (Figure 1), a frequency comb generates a series of 16 optical wavelengths (spaced $12.5 \mathrm{GHz}$ ) using amplitude modulation (AM) from a continuous wave laser (CW) centered at $193.1 \mathrm{THz}$ (line width $100 \mathrm{kHz}$ ). The CW supplies a two-arm MZM controlled by a sinusoidal signal generated at $12.5 \mathrm{GHz}$. Each branch is controlled by a sinusoidal signal in phase with a specific amplitude interval as detailed in [13]-[18]. The 16 optical wavelengths are demultiplexed using a DEMUX to individually modulate the signal. The modulated signal is transposed into intermediate frequencies $(\mathrm{IF} 1=8.32 \mathrm{GHz}, \mathrm{IF} 2=10.48 \mathrm{GHz}, \mathrm{IF} 3=2.64 \mathrm{GHz}$ and IF4 $=4.8 \mathrm{GHz}$ ) by considering modulation formats such as BPSK, QPSK and 16QAM with data rates up to $5.28 \mathrm{GHz}$. The four intermediate frequency (IF) 


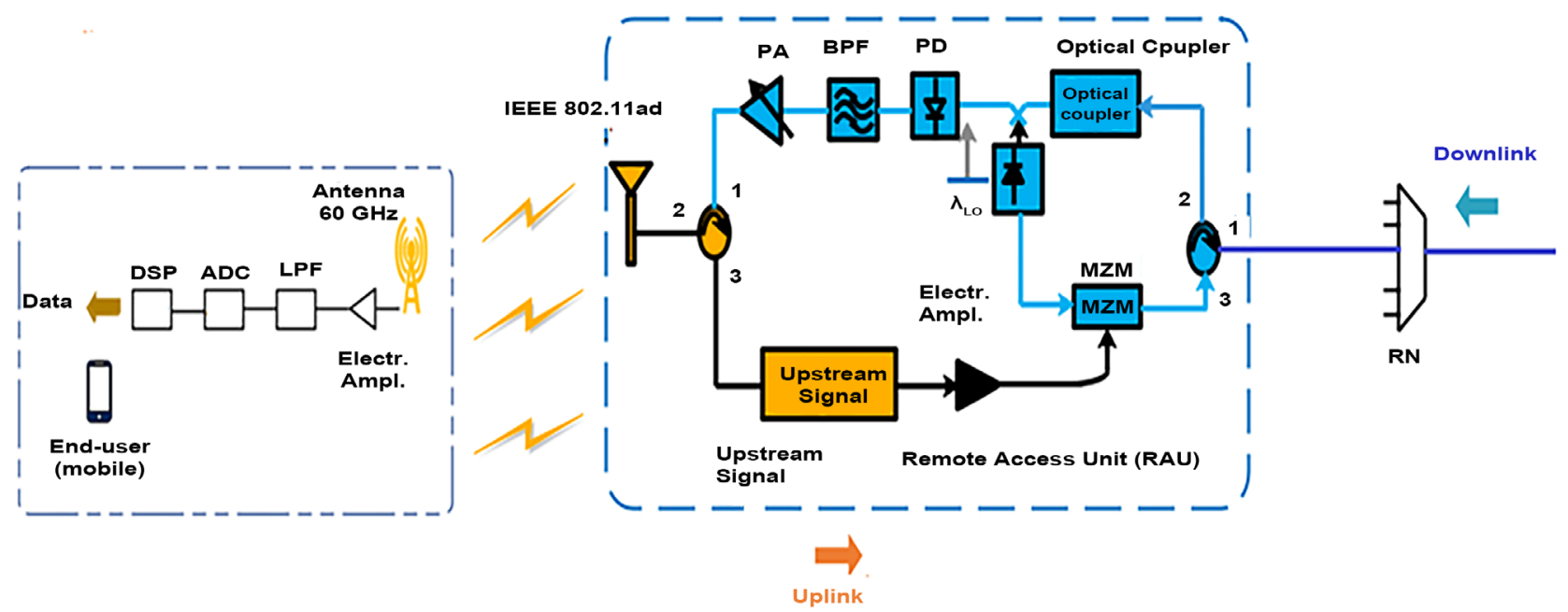

Figure 2. Architecture of the remote access node (RAU) and the demultiplexer (RN). 
circulator separates the upward optical signal from the downward optical signal. The upstream optical signal is photodetected, amplified and modulated offline using a DSP to measure its error rate.

\section{Result of the Simulation and Discussion}

In this experiment, we use Optisystem (Optiwave) and Advanced Design System (Agilent) software to implement and simulate the optical and radio links of the proposed RoF system respectively. The performance of the proposed system was assessed by measuring the EVM at the end-user level. We consider an indoor environment of $32 \mathrm{~m}$ and modulation formats BPSK (1.65 Gbps), QPSK (3.3 Gbps) and 16 QAM (5.28 Gbps). To study performance, we evaluated EVM at the end-user (MU) level based on the capabilities of the RoF system (number of channels) and the radio distance by simulating several scenarios. We also studied the achievable data rate and the effect of capacities (number of channels) on the performance of the proposed RoF system. We assume a transmit antenna gain (RAU) of $19 \mathrm{~dB}$ and a receive antenna gain of $10 \mathrm{~dB}$ (end user). Figure 3, Figure 4 and Figure 5 illustrate the evolution of EVM as a function of radio capacity and radio distance for each modulation format (BPSK, QPSK and 16 QAM).

We observe that the simulated EVM respects the EVM thresholds for all modulation formats. The wireless radio distances obtained during the simulation meet the requirements of the WLAN environment. The small difference between the simulated distances and the theoretical distances may be due to the fact that the 802.15.3c standard adopts bit error correction (FEC) reducing the default bits in order to improve the quality of the link. It is noted that, when the system capacity increases (increase in the number of channels, that is to say, the speed of the global networks), the EVM is not deteriorated (the performance of the

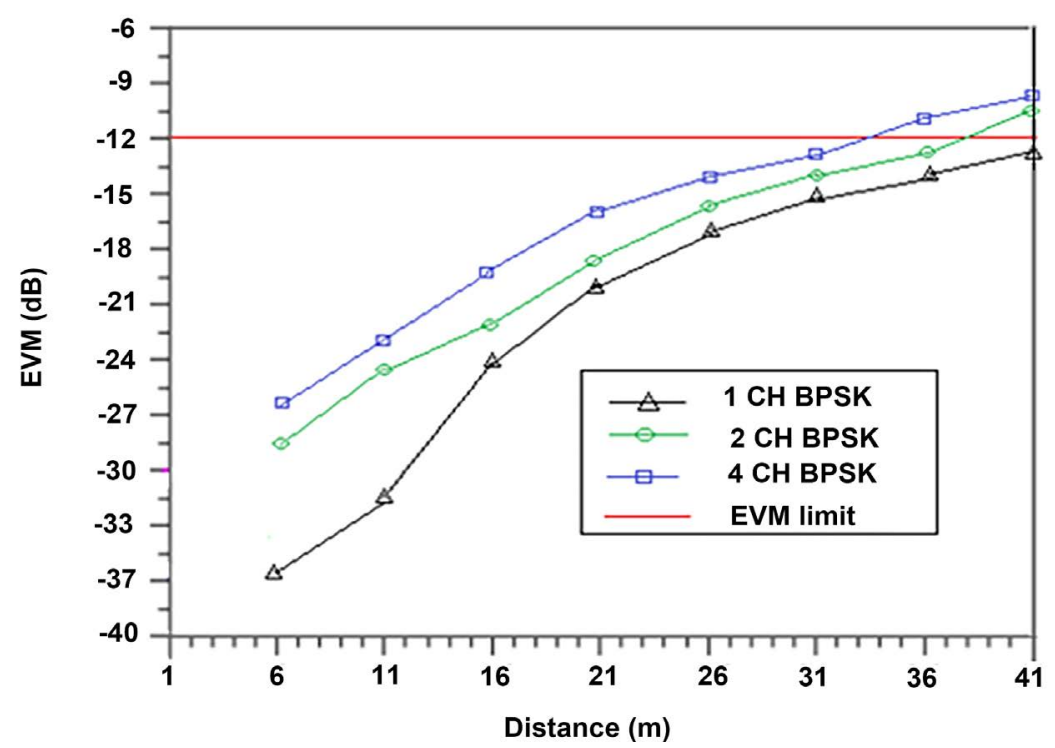

Figure 3. EVM versus radio distance for BPSK modulation. 


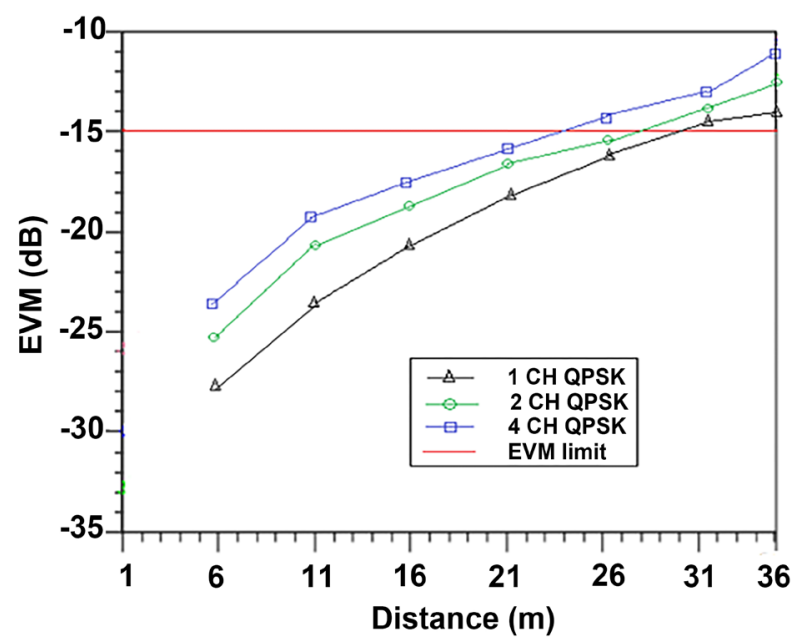

Figure 4. EVM versus radio distance for QPSK modulation.

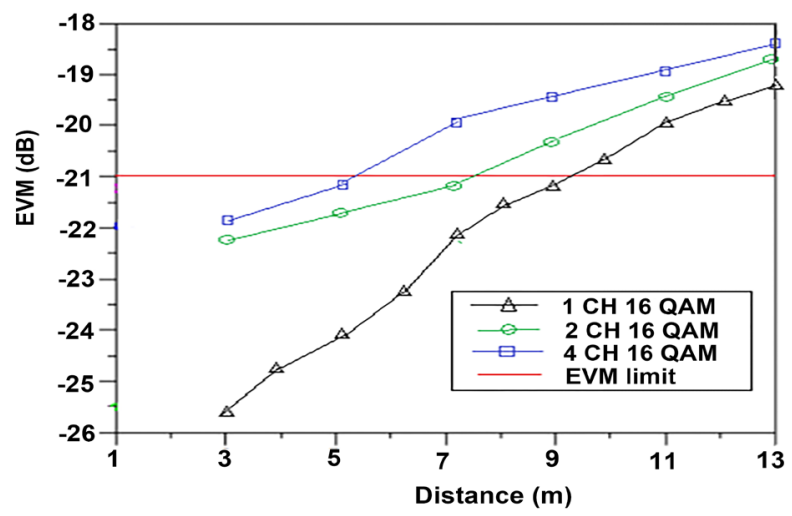

Figure 5. EVM versus radio distance for 16 QAM modulation.

system remains maintained). So the proposed RoF architecture can operate at full capacity without major impact on the radio link.

The simulated radio distances for various modulation formats (BPSK, QPSK and 16 QAM) are matched with Theoretical results, as shown in Table 1. The difference between the calculated radio distance and the simulated radio distance for the limit of the EVM is acceptable. The most affected flow is the 16 QAM modulated data flow ( $12.5 \mathrm{~m}$ and $5.5 \mathrm{~m}$ respectively for theoretical and simulated distances). This is probably due to the susceptibility of 16 QAM modulations to intermodulation, noise and attenuation. However, the simulated distance is aligned with RoF studies, in particular [18].

We also studied the performance of the proposed system by evaluating the EVM compared to the power received at the end-user level. These results are represented in Figure 6, Figure 7 and Figure 8. We note that the EVM simulated at the receiver sensitivity generally exceeds the limits defined by the 802.15.3C standard at the transmission level in Table 2. The simulated EVM is approximately $-16 \mathrm{~dB}$ for a $16 \mathrm{QAM}$ signal at $5.28 \mathrm{Gbps}$ and assuming receiver sensitivity equal to $-46 \mathrm{dBm}$. To obtain an acceptable EVM $(-21 \mathrm{~dB})$, the 
Table 1. Simulated RoF system performance.

\begin{tabular}{ccccc}
\hline Modulation & EVM limit [18] & Data rate & Theoretical distance & Simulated distance \\
\hline BPSK & $-12 \mathrm{~dB}$ & $1.65 \mathrm{dBm}$ & $40 \mathrm{~m}$ & $32 \mathrm{~m}$ \\
QPSK & $-15 \mathrm{~dB}$ & $3.3 \mathrm{dBm}$ & $27 \mathrm{~m}$ & $23 \mathrm{~m}$ \\
16 QAM & $-21 \mathrm{~dB}$ & $5.28 \mathrm{dBm}$ & $12.5 \mathrm{~m}$ & $5.5 \mathrm{~m}$ \\
\hline
\end{tabular}

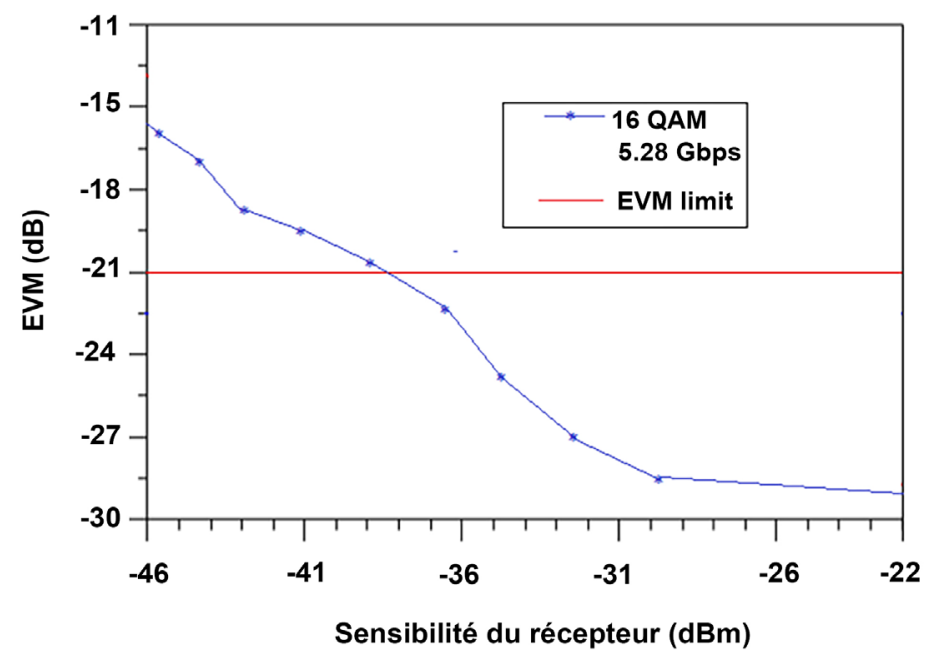

Figure 6. EVM versus power received for the $16 \mathrm{MAQ}-5.28 \mathrm{Gbps}$ signal.

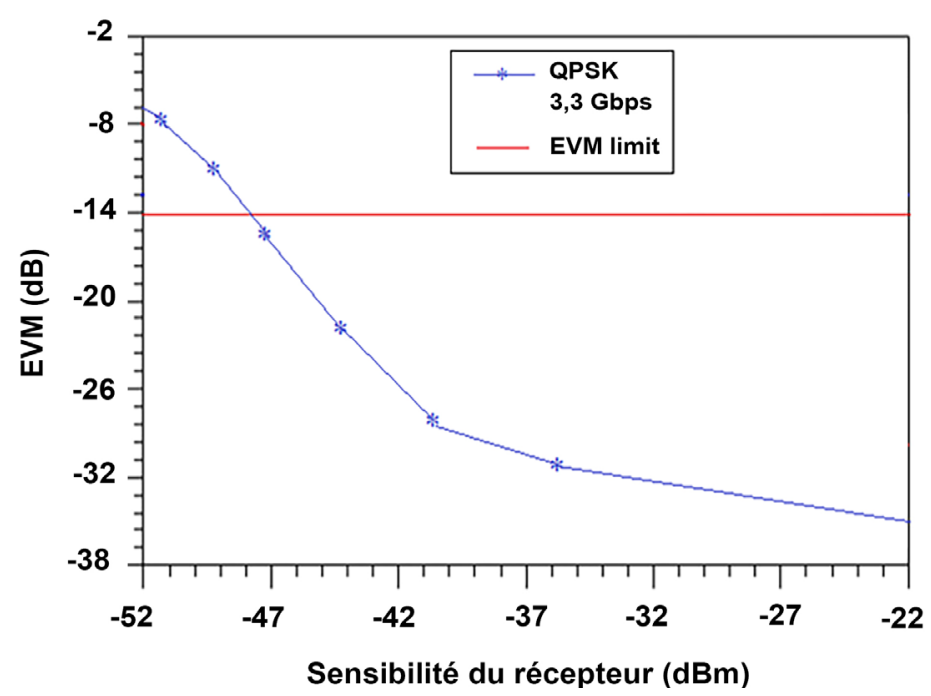

Figure 7. EVM versus received power for QPSK-3.3 Gbps signal.

received power is approximately $-38 \mathrm{dBm}$. The simulated EVM is approximately $-4 \mathrm{~dB}$ for the BPSK signal at the receiver sensitivity, although the acceptable EVM for the BPSK signal is $-7 \mathrm{~dB}$. We note that the sensitivity of the simulated receiver is greater in the case of 16 QAM modulations, due to the sensitive modulation format and the imperfection introduced by the fiber with a length of 50 $\mathrm{km}$. The simulation results are acceptable and show the usefulness of the proposed RoF architecture. 


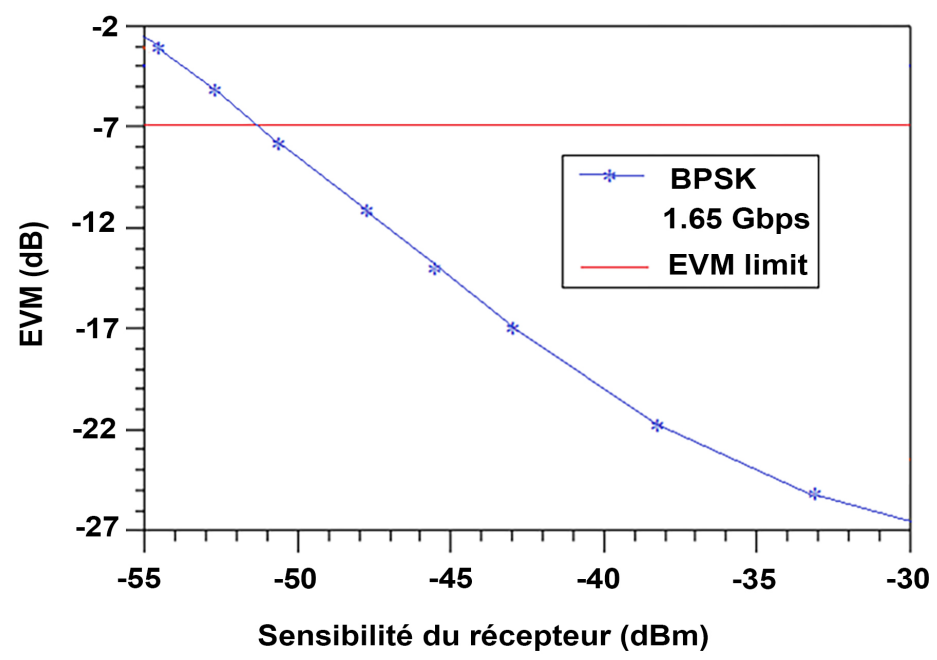

Figure 8. EVM versus received power for BPSK-1.65 Gbps signal.

Table 2. Specification of millimeter wave services [15].

\begin{tabular}{cccc}
\hline Modulations & Data rates (Gbps) & EVM limit at (BTS) & Receiver sensitivity \\
\hline BPSK & 1.65 & $-7 \mathrm{~dB}$ & $-55 \mathrm{dBm}$ \\
QPSK & 3.3 & $-14 \mathrm{~dB}$ & $-52 \mathrm{dBm}$ \\
16 QAM & 5.28 & $-21 \mathrm{~dB}$ & $-46 \mathrm{dBm}$ \\
\hline
\end{tabular}

\section{Conclusion}

In this study, we proposed a RoF system in association with the unlicensed 60 $\mathrm{GHz}$ band for very high-speed wireless communications. It is also adapted to the concept of small cells and for centralized management in next generation hybrid networks. Millimeter compatible wireless signals are properly distributed to RAU. We studied the performance of the proposed system by evaluating the EVM as a function of radio distance and received power. We simulated the entire system's EVM by considering multi-format modulation (BPSK, QPSK and 16 QAM) with data rates of up to $5.28 \mathrm{Gbps}$. We demonstrate an optical link distance of $50 \mathrm{~km}$ and maximum radio coverage of $32 \mathrm{~m}$ assuming an indoor environment. The EVM simulated at different receiver sensitivities exceeds the limits defined by the IEEE 802.15.3c standard. This study made it possible to highlight ROF architecture with an optical transmission on and radio coverage by considering the uplink and downlink. The results of the simulations are satisfactory and encouraging. Thanks to this system, we were able to deliver millimeter wave signals over a $50 \mathrm{~km}$ fiber link and a wireless channel up to $32 \mathrm{~m}$ with a data rate of up to $5.28 \mathrm{Gbps}$. These results demonstrate the performance of the proposed RoF architecture to meet the growing demands of broadband applications and high capacity networks. We hope that architecture can be upgraded to meet other licensed millimeter frequency bands with little hardware modification. 


\section{Conflicts of Interest}

The authors declare no conflicts of interest regarding the publication of this paper.

\section{References}

[1] Xi, L., Vitaly, P., Dmitri, M., Sergey, A., Toktam, M. and Mischa, D. (2017) Conceptualizing Integrated Utilization of Licensed and Unlicensed Spectrum for Future IoT. IEEE Communication Magazine, 55, 64-71.

[2] http://www.wirelesshd.org/ http://www.wirelesshd.org/pdfs/WirelessHD-Specification-Overviewv1.1May2010p df

[3] Jia, Z., Yu, J., Ellinas G. and Chang, G.K. (2007) Key Enabling Technologies for Optical-Wireless Networks: Optical Millimeter-Wave Generation, Wavelength Reuse, and Architecture. Journal of Lightwave Technology, 25, 3452-3471. https://doi.org/10.1109/JLT.2007.909201

[4] Liu, C., Zhang, L., Zhu, M., Wang, J., Cheng, L. and Chang, G. (2013) A Novel Multi-Service Small-Cell Cloud Radio Access Network for Mobile Backhaul and Computing Based on Radio-Over-Fiber Technologies. Journal of Lightwave Technology, 31, 2869-2875. https://doi.org/10.1109/JLT.2013.2274193

[5] Al-Musaw, H.K., Ng, W.P., Ghassemlooy, Z., Lu, C. and Lalam, N. (2015) Experimental Analysis of EVM and BER for Indoor Radio-over-Fibre Networks Using Polymer Optical Fibre. 2015 20th European Conference on Networks and Optical Communications (NOC), London UK. https://doi.org/10.1109/NOC.2015.7238624

[6] Weng, C., Lin, Y. and Way, W. (2008) Radioover-Fiber 16-QAM, 100-km Transmission at $5 \mathrm{~Gb} / \mathrm{s}$ Using DSB-SC Transmitter and Remote Heterodyne Detection. Journal of Lightwave Technology, 26, 643-653.

https://doi.org/10.1109/JLT.2007.912526

[7] Dat, P.T., Kanno, A. and Kawanishi, T. (2015) Radio on Radio over Fiber: Efficient Front Hauling for Small Cells and Moving Cells. IEEE Wireless Communications, 22, 67-75. https://doi.org/10.1109/MWC.2015.7306539

[8] Novak, D., Waterhouse, R.B., Nirmalathas, A., Lim, C., Gamage, P.A., Clark, T.R., Dennis, M.L. and Nanzer, J.A. (2016) Radio-over-Fiber Technologies for Emerging Wireless Systems. IEEE Journal of Quantum Electronics, 52, 1-11. https://doi.org/10.1109/JQE.2015.2504107

[9] Chang, G.K., Liu, C. and Zhang, L. (2013) Architecture and Applications of a Versatile Small-Cell, Multi-Service Cloud Radio Access Network Using RadioOver-Fiber Technologies. 2013 IEEE International Conference, Budapest, Hungary, 879-883.

[10] Domenico, P. and Walter, H. (2003) Ultra-Wideband Radio Technology: Potential and Challenges Ahead. IEEE Communications Magazine, 41, 66-74. https://doi.org/10.1109/MCOM.2003.1215641

[11] Lorente, R., Walker, S., Monroy, I.T., Beltran, M., Morant, M., Quinlan, T. and Jensen, J.B. (2011) Triple-Play and 60-GHz Radio-over-Fiber Techniques for Next-Generation Optical Access Networks. 2011 16th European Conference Networks and Optical Communications (NOC), Newcastle, 16-19.

[12] Ming, Z., Zhang, L., Wang, J., Cheng, L., Liu, C. and Chang, G.K. (2013) RadioOver-Fiber Access Architecture for Integrated Broadband Wireless Services. Journal of Lightwave Technology, 31, 3614-3620. 
https://doi.org/10.1109/JLT.2013.2286564

[13] Sarra, R., Rim, B. and Mourad, M. (2016) Software Defined Networking for Cognitive Radio over Fiber Systems. 2016 IEEE Wireless Communications and Networking Conference Workshops ( WCNCW), Doha Qatar.

[14] Ghazisaidi, N., Scheutzow, M. and Maier, M. (2011) Survivability Analysis of NextGeneration Passive Optical Networks and Fiber-Wireless Access Networks. IEEE Transactions on Reliability, 60, 479-492. https://doi.org/10.1109/TR.2011.2134210

[15] ECMA International (2010) High Rate $60 \mathrm{GHz}$ PHY, MAC and PALs. Standard ECMA.

http://www.ecmainternational.org/publications/files/ECMAST/ECMA-387.pdf

[16] IEEE 802.15.3C (2009) Wireless Medium Access Control (MAC) and Physical Layer (PHY) Specifications for High Rate Wireless Personal Area Networks (WPANs). Amendment 2: Millimeter-Wave-Based Alternative Physical Layer Extension. https://ieeexplore.ieee.org/servlet/opac

[17] Introduction to $\mathrm{Wi}-\mathrm{Fi}$ (802.11 or $\mathrm{WiFi})$ (2014) http://en.kioskea.net/contents/802-introduction-to-wi-fi-802-11-or-wifi

[18] IEEE 802. 11 (2012) Part 11: Wireless LAN Medium Access Control (MAC) and Physical Layer (PHY) Specifications. 